\title{
Correction to: Health-related quality of life in Chinese workers: a systematic review and meta-analysis
}

\author{
Ya Su ${ }^{1,2,3}$, Meng-Shuang Liu'1,2,3, Pinnaduwage Vijitha De Silva ${ }^{4}$, Truls Østbye ${ }^{5}$ and Ke-Zhi Jin ${ }^{1,2,3^{*}}$ (i)
}

\section{Correction to: Global Health Research and Policy (2021) 6:29 https://doi.org/10.1186/s41256-021-00209-z}

Following publication of the original article [1], it is reported that there were errors in the first author's name and the third affiliation.

The incorrect author's name is "By Ya Su".

The correct author name is "Ya Su".

The incorrect affiliation is:

${ }^{3}$ Fudan Global Health Institute, Shanghai, People's Republic of China.

The correct affiliation is:

${ }^{3}$ Fudan Global Health Institute, Fudan University, Shanghai, People's Republic of China.

The first author name and the third affiliation have been corrected above and the original article [1] has been updated as well.

\section{Author details}

'Department of Occupational Health, School of Public Health, Fudan University, 138 Yixueyuan Road Box288\#, Shanghai 200032, People's Republic of China. ${ }^{2}$ Key Laboratory of Public Health Safety, Ministry of Education, Shanghai, People's Republic of China. ${ }^{3}$ Fudan Global Health Institute, Fudan University, Shanghai, People's Republic of China. ${ }^{4}$ Department of Community Medicine, University of Ruhuna, Galle, Sri Lanka. ${ }^{5}$ Duke Global Health Institute, Durham, NC, USA.

Published online: 03 September 2021

\section{Reference}

1. Su Y, Liu MS, De Silva PV, et al. Health-related quality of life in Chinese workers: a systematic review and meta-analysis. Glob health Res policy. 2021;6:29. https://doi.org/10.1186/s41256-021-00209-z.

\section{Publisher's Note}

Springer Nature remains neutral with regard to jurisdictional claims in published maps and institutional affiliations. to the material. If material is not included in the article's Creative Commons licence and your intended use is not permitted by statutory regulation or exceeds the permitted use, you will need to obtain permission directly from the copyright holder. To view a copy of this licence, visit http://creativecommons.org/licenses/by/4.0/. 